Nuestro arte va a buscar la realidad social, a descubrir una cultura americana, no a inventarla. Este es problema fundamental para toda mente realista que sepa ver con claridad. América no le debe absolutamente nada a Europa, a no ser a aquellos occidentalistas débiles y confusionistas, cuyo desconocimiento de la realidad los hace sentimentalmente románticos. Así en poesía como en política, sobre todo en política.

Sólo creándonos una cultura, un arte propio, sin influencias ajenas, podremos medir el desenvolvimiento, el desarrollo, la fuerza continental de nuestros pueblos.

Una cultura, un arte americanos, del pueblo y para el pueblo, se convertirán en universales. Ahí donde el hombre encuentra su expresión está la poesía iluminada for la creación del pensamiento humanista. La poesía así con energía, fuerza y carácter nos está señalando el camino que abre a la cultura de la humanidad. Crear una poesía varonil americana, cuanto más nuestra sea, tendrá valor de contribución para la historia. Primero es el pensamiento, después es la belleza. El pensamiento no tendrá otra forma de expresión artística que ésta: americana en su raíz. «El porvenir está en el cerebro. Después vienen los músculos»-dice Gladkov. -SERAFÍ DE L MAR.

\title{
El panorama de Max Daireaux
}

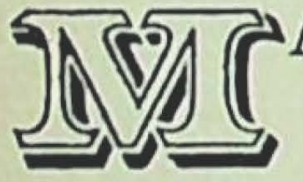

AX Daireaux, escritor francés hijo de americana, ha publicado un panorama de la literatura hispanoamericana (1) que merece en realidad un detenido comentario. Es un esfuerzo considerable, no se podría negar; pero sus deficiencias son también considerables. $\mathrm{El}$ autor revela conocimiento global de la literatura americana; comprende cuáles son los rasgos característicos de este proceso literario y hasta trata algunas figuras con extraordinaria elevación de miras y con verdadero dominio de la materia. Pero en lo particular yerra con frecuencia, como se verá más adelante. Recoger todos sus yerros nos ocuparía demasiado espacio. Nos conformaremos, pues, con examinar los que ha cometido el autor al mencionar a los escritores chi-

(1) Ediciones Kra. París, 1930. 
lenos, y para no extender desmesuradamente estas líneas creemos conveniente entrar en materia de inmediato.

El autor divide el continente americano en cuatro porciones. En la primera porción figura sólo Chile, que elogia por su sobriedad, su gusto del estudio y el valor de sus escritores de historia y sociología.

Rude pays-dice (pág. 18)-de miniers et de marins, il a le culte de l'action et de la force, et le goût de l'étude.

En un segundo grupo quedan los países del Plata: Argentina, Uruguay y Paraguay. (Sobre éste, por lo demás, no da más adelante mención alguna.) En un tercer grupo se juntan Bolivia y Perú. El cuarto lo componen las naciones en que se dividió la Gran Colombia: Ecuador, Colombia y Venezuela.

A todo esto el lector habrá observado algo curioso: no se ha nombrado a ningún país centro-americano, ni al Brasil, ni a las Antillas, ni a México, que literariamente es una de las naciones más importantes de la comunidad hispano-americana. Daireaux tiene una doctrina especial, y nada plausible, sobre la materia. No incluye al Brasil por el hecho de no ser el español la lengua nacional; hace caso omiso de las Antillas (aun cuando cita con elogio, de paso, a Martí); cita a algunos escritores de la América Central (¿cómo podría ser de otra manera si Rubén Darío era nicaragüense?), pero excluye a México en un movimiento de humor que es simplemente incomprensible:

Enfant turbulent, inquiet et lyrique (1), à la fois positiviste et vissionnaire, réaliste et chimérique, élégiaque et cruel, le Méxique s'est volontairement séparé de la famille latino-américaine, et ne consentirait à s'y joindre que pour réclamer dans le domaine spirituel les prérogatives impérialistes inhérentes au droit d'aînesse. (Pág. 17.)

El lector debe preguntarse, como yo me pregunté durante mucho rato, si no ha leído mal. Realmente parece difícil dar prueba de tanta ignorancia de las cosas americanas en tan pocas palabras. Vamos por partes.

1. - Las primeras expresiones (enfant turbulent, à la fois positiviste et chimérique) convienen tanto a México como a cualquier otro país americano, si se exceptúa Chile, donde la nacionalidad se consolidó antes que en país alguno de Amé-

(1) ¿Lyrique nada más? Y la estupenda novelística mexicana, ¿dónde queda? ¿Y sus pensadores, estetas y sociólogos? 
rica y donde si hubo y hay positivismo, lo quimérico siempre lia faltado.

2. ¿En qué sentido puede decirse que México se ha sepa+ rado voluntariamente de la familia latino-americana? ¿En el político? La familia latino-americana (ya nos haremos cargo de esta entelequia) está compuesta de unidades autónomas y ningún pacto explícito le da cohesión. México ha resistido al imperialismo yanqui, como cualquier otro país de América que se haya visto amenazado. Eso no es apartarse de la familia americana, si no tal vez lo contrario. ¿En el literario? Sin una declaración explícita de no seguir ligado con el resto del continente, México permanece atado a él por la sólida traba de la lengua. Hay más: varias generaciones de mexicanos han influido poderosamente en las letras de América. Aunque hubiesen pretendido separarse los mexicanos, la fuerza de su genio y su formidable originalidad les habrían concedido una especie de primogenitura espiritual que los demás americanos reconocen gustosos. Por lo demás, Vasconcelos estampó cuando fué Ministro de Educación la frase: "Por mi raza hablará el espíritu» sobre un mapa de todos los países ibero-americanos-incluso Brasil-. ¿Hay aquí un anhelo separatista? Me parece que no.

3. Esto de la familia latino-americana son paparruchas bastante viejas y torpes, y los americanos sabemos ya a qué atenernos. Los hombres de este continente se sienten hispano-americanos y no latino-americanos. ¿La influencia de la latinidad? Enorme, si se quiere; pero la raza no es latina, y eso debe bastar.

4. Suponer que México al volver a la comunidad que tan peregrinamente se dice que ha abandonado, reclamará en el dominio espiritual prerrogativas imperialistas, me parece a mí una invención harto fantástica. Esto es simplemente desbarrar.

$* * *$

Para orientarse en la vasta maraña de temas que le ofrecía su materia, el señor Daireaux ha escogido el camino que presenta más inconvenientes. En efecto, después de haber agrupado a los países americanos en la forma comentada, abandona la división geográfica, que podría tener una justificación en los caracteres similares que presenta la literatura en cada uno de los países que compone cada grupo. En lugar de esta división acomete la división por géneros 
literarios, que es sin duda la más arbitraria en un caso como el presente.

Es preciso tener en cuenta que los países americanos le parecen al lector medio europeo una cosa amorfa, no bien determinada; algo como provincias de un gran imperio. Sin un cabal sentido de las distancias, cree que entre Caracas y Buenos Aires hay poco trecho y que de Valparaíso se puede ir a Río de Janeiro en pocas horas. Pues bien, para lectores de este género indicar simplemente que Blanco Fombona es venezolano y Gabriela Mistral chilena, es algo muy insuficiente. Por lo demás, los países americanos tienen ya una individualidad literaria más o menos acentuada, individualidad que en algunos arranca desde la misma Colonia. Por ejemplo, un movimiento literario tan poderoso como el modernismo, que influyó por parejo y en poco tiempo en América toda, tuvo modalidades nacionales que no se pueden desconocer. No cabe duda de que los modernistas argentinos (Lugones, Díaz, etc.) no sólo se asemejan mucho entre sí, sino que además forman una capilla aparte dentro del modernismo.

Por encima de esto pasa el señor Daireaux sin parar mientes. La división por géneros no le permite hacer esas divisiones más o menos sutiles, pero sin las cuales no hay crítica literaria seria, y sus enumeraciones de poetas y escritores son simples amontonamientos de nombres que no dicen ni dirán nada al lector europeo.

$$
\text { **** }
$$

El capítulo de la novela chilena y algunas otras referencias al mismo tema hierven de errores, que conviene ir mencionando uno por uno para ilustración del señor Daireaux y de sus irresponsables y aviesos informantes.

1. Pág. 25: Un romancier chilien Barrios, qui est à coup sûr l'un des maîtres de la prose sud-américaine, est à peu près inconnu à Buenos Aires.

¡Lástima de flecha perdida! Daireaux quiso dar en el blanco y no pasó ni cerca. Si hay sitio en el mundo en que nuestro novelista sea conocido y apreciado (después de Chile, su patria, se entiende), ese sitio es Buenos Aires. Las pruebas: hay ediciones argentinas nada menguadas de Un perdido y El hermano asno; un libro de cuentos de Barrios, Y la vida sigue...., se ha publicado sólo en Buenos Aires; las edicio- 
nes españolas de los dos libros mencionados y el de $E l$ niño que enloqueció de amor han circulado mucho en la capital platense; en revistas y libros aparecidos en Buenos Aires (1) se ha comentado detenidantente la obra de Barrios. ¿Qué más? Barrios ha sido colaborador de La Nación de Buenos Aires, donde se publicaron algunos de sus cuentos y artículos.

2. Pág. 191: Au Chili, Rosario Uribe de Orrego fut la créatrice du roman; elle est antérieure à Alberto Blest Gana, qui fut un des meilleurs écrivains du Pacifique....

Demasiado feminismo, y feminismo muy innecesario. $A l$ berto el jugador, el libro novelesco de la señora Orrego de Uribe (y no al revés como trae Daireaux), apareció en 1861, prologado por don Ricardo Palma, que con mucha benevolencia no vacila en elogiar desmedidamente a la autora.

La verdad es que este libro está hoy enteramente olvidado y que don Alberto Blest Gana es considerado por la crítica chilena como el padre de la novela. Engaños y desengaños, el primer libro de Blest Gana, que es una novela, y El primer amor, que también lo es, aparecieron en 1858. ¿Cómo va a ser anterior a Blest Gana la señora Orrego si su novela apareció sólo en 1861? Francamente, el señor Daireaux se ha pasado de galante.

3. Pág. 219: Son roman Cap Polonio (se refiere a Joaquín Edwards Bello) connut un succès inmédiat.... Son second livre, Un chilien à Madrid lui a fourni une double satire assez savoureuse....

Error sobre error. Ni Cap Polonio es el primer libro de Edwards Bello, como da a entender la calificación de «second livre aplicada a El chileno en Madrid, ni en este libro hay ese carácter satírico predominante que quiere destacar Daireaux. Es cierto que el genio de Edwards Bello tiende no pocas veces a la sátira. Pero el tono que prevalece en $E l$ chileno en Madrid no es el satírico sino el sentimental. ¿No ha leído este libro el autor del panorama?

4. Pág. 235: Les conteurs chiliens ont peu exploté la veine locale. Guillermo Labarca Hubertson dans son roman Les crépuscules et dans ses contes De la terre a tenté de le faire.

(1) En este momento recuerdo los libros de E. Suárez Calimano y Luisa Luisi, donde se leen estudios sobre nuestro compatriota. En las revistas argentinas Nosotros, Nuestra América, etc. se han publicado también artículos sobre sus libros. 
No señor. Los cuentistas chilenos se han dedicado con predilección a la veine locale. Todos los medios, y entre ellos particularmente los populares, donde el localismo, como se comprenderá, es absorbente, han sido escarbados por los cuentistas para sus temas. Si esto no es explotar la veine locale yo no sé qué nombre darle.

Por lo demás, las noticias que se dan sobre Guillermo Labarca Hubertson nos llenan de sorpresa. No se cita su hermosísimo libro Mirando al Océano y en cambio se le atribuyen estos Crépuscules y De la Terre. Conviene advertir que el título preciso de este último libro es $A l$ amor de la tierra.

5..$^{\circ}$ Pág. 271: .... et le jeune romancier Eugenio Labarca dont les études critiques pleines de finesse ont une grâce singulière, une légèreté de touche assez peu commune en Amérique.

Este joven novelista, que debe haber aprovechado su presencia en París para influenciar a Daireaux, en realidad cs autor de una muy mediocre novela de clave, sobre la acic! se dijo en su oportunidad todo lo que merecía, y su posición dentro del panorama actual de la literatura chilena es secundaria. Es una lástima que el señor Daireaux esté tan lejos. Si se diera una vuelta por aquí vería que el lugar que ocupa su elogiado en las letras nacionales no es brillante ni mucho menos, y que esos estudios críticos en los cuales el autor del panorama ha creído ver cualidades tan interesantes, son unos pobres articulitos de miscelánea literaria, en parte traducidos del francés y en parte rosarios de cándidas exclamaciones que nada tienen de crítico aunque sí mucho de gracioso.

$* * *$

Que la poesía no acapara toda la atención de los escritores de este continente lo sabe muy bien el señor Daireaux. Bastaría el ejemplo de Chile y de la Argentina, que tienen más prosistas que poetas en el siglo XIX (se entiende más prosistas importantes), y acaso el de Colombia, donde hay oradores y críticos y gramáticos de fuste, para probar que la frase siguiente es un error craso:

Ecrire l'histoire de la poésie sudaméricaine, c'est écrire l'histoire même de sa liitérature. (Pág. 59.)

Con este peregrino criterio la literatura chilena del siglo pasado se reduce a polvo, si se tiene en cuenta que ni Las- 
tarria, ni Barros Arana, ni Sotomayor Valdés, ni Miguel Luis Amunátegui, ni Alberto Blest Gana, ni Barros Grez, ni Jotabeche, ni los Arteaga Alemparte, ni Daniel Riquelme, ni Vicuña Mackenna, ni Pérez Rosales, ni Blanco Cuartín, que algo representan dentro del movimiento intelectual de América, escogieron la forma rimada para sus más importantes producciones. $Y$ conste que en la enumeración hay algunos que no escribieron en su vida sino dos o tres composiciones en verso, en los días de la iniciación, cuando el rumbo literario no ha sido fijado todavía claramente.

Pero cuando se ha dicho que escribir la historia de la poesia sud-americana es escribir la historia misma de su literatura, nada tiene de raro encontrar este juicio peregrino (pág. 148):

Pezoa Veliz (sic) et Victor Domingo Silva n'apportent à la poésie aucune nouveauté.

Esto es, por lo menos, demasiado radical. ¿Quién ha guiado la pluma del señor Daireaux para hacerie cometer semejante disparate? Abra el autor de este panorama cualquier estudio sobre poetas chilenos, lea algunos de los principales poemas de Pezoa Velis y verá cuánto hay de nuevo allí. Recuérdese que Pezoa Velis murió hace ya más de veinte años; estúdiese, siquiera grosso modo, el rumbo general de la literatura de su tiempo, y se entenderá cuánto fué lo nuevo que aportó Pezoa a las letras chilenas y qué valioso fué su mensaje. Es preciso advertir que Pezoa se inicia cuando el estéril cascabeleo rítmico de Pedro Antonio González domina la sensibilidad chilena. Fragmentos como Nada, Tarde en el hospital, Fecundidad, tenían que sonar a nuevo y muy a nuevo en esos días. Es cierto que Pezoa, cuyo gusto literario es muy inseguro, rima también en sus momentos de ocio poemas de puro tamborileo verbal. Pero eso no anula el resto de su obra.

Sobre Víctor Domingo Silva también se podría alegar algo, y mucho; pero creo que él mismo podrá defenderse con buenas razones literarias.

Mucho más se podría decir sobre este curioso panorama, tan inconexo e indocumentado como el lector podrá apareciar por las muestras. El capítulo de la poesía es, en lo que toca a Chile, de una pobreza franciscana y de una lamentable injusticia. (Hablo en general: las menciones dedicadas a Ga- 
briela Mistral y a Pablo Neruda están bien.) En el periodismo se ven menciones del más subido color cómico. Entre los historiadores y sociólogos no aparece nuestro don José Victorino Lastarria, que es figura cardinal del siglo XIX. Pero desmenuzar todo esto nos llevaría muy lejos; habría en realidad que escribir de nuevo todo el panorama.

$\mathrm{Y}$ esto no es nuestra misión. Creemos haber cumplido con nuestro deber sacando a la pública vergüenza un libro que en realidad no deshonra a la crítica francesa puesto que ella se ha distinguido siempre por su incomprensión de todo lo extranjero y por su olímpico «je-m'en-fichisme hacia todo lo que no es francés. Pero que es incomprensible en un escritor que tiene algo -y mucho- de sangre americana y al cual los americanos deberíamos considerar en cierto modo como hombre de nuestra raza.-R. S I L V A CA S T R O.

\section{Crónica de espectáculos}

PREPARATIVOS PARA LA TEMPORADA LÍRICA.- ¿POR QUE NO SE ENTREGA EL TEATRO MUNICIPAL A UNA EMPRESA PRIVADA?-NUEVAMENTE LA CENSURA CINEMATOGRĀFICA: $: S H E-$ REZADA $Y$ \&FECUNDIDAD».

(7) JODOS los años, al acercarse el invierno, se hacen preparativos para la temporada lírica que debe realizarse en nuestro Teatro Minicipal y se anuncia, con caracteres sensacionales, el elenco que debe actuar en él. Este procedimiento se ha generalizado tanto que nadie protesta del engaño que significa y los abonados se conforman resignadamente con las mediocridades que les presentan, para suplir a los artistas de celebridad mundial que se anuncian y que, por una u otra causa, no llegan a Chile. De acuerdo con esta tradición, y tomando en cuenta la experiencia de años anteriores, en los cuales el Fisco ha debido cubrir crecidos déficits engendrados por temporadas mal organizadas, la Municipalidad ha enviado un comisionado a Europa para contratar directamente el elenco que deberá actuar en la próxima temporada. Dicho comisionado, que aún no regresa, ha anunciado estruendosamente el contratoque se dice ya finiquitado-con Chaliapin y Claudia Muzio. 